En pro de la Religión y de la dignidad humana | 339

\title{
En pro de la Religión y de la dignidad humana. Las fuentes chilenas de la encíclica "Lacrimabili statu Indorum» de Pío X y la solicitud pastoral de la Santa Sede*
}

\author{
Mario L. Grignani \\ PONTIFICIA UNIVERSIDAD URBANIANA \\ CIUDAD DEL VATICANO
}

En pro de la Religión y de la dignidad humana: con estas palabras el Papa Pío X terminaba su encíclica Lacrimabili statu Indorum firmada el 7 de

\footnotetext{
El artículo es un primer resultado de la investigación financiada por el VIII Concurso de Investigación para Académicos UC (Vicerrectoría de Investigación y Dirección de Pastoral y Cultura Cristiana de la Pontificia Universidad Católica de Chile - proyecto N04/DPCC2010); investigador principal: Mario L. Grignani, ayudantes: Lic. Monge Allen, Exequiel Leopoldo Arturo y Salgado Alarcón, María Paz. Agradezco a los Directores y Archiveros de los archivos consultados por su cordialidad y orientaciones, especialmente en Chile: Srta. Arlette Marielle Libourel (AArS); Fr. Sergio Uribe O.F.M.C. (ACS); Fr. Rigoberto Iturriaga O.F.M. (AFS); Prof. Salvatore Cirillo (AMBPA); P. Eugene Rooney S.J. (AJS); P. Simón Kuzmanich, S.D.B. (ASS). Siglas: AAS (Acta Apostolicae Sedis, Roma), AArS (Archivo Histórico de Arzobispado, Santiago), ACS (Archivo de la Orden Franciscana de los Frailes Menores Capuchinos, Santiago), AFS (Archivo de la Orden Franciscana de los Frailes Menores, Santiago), AMBPA (Archivo del Museo Regional "Maggiorino Borgatello", Punta Arenas), APF (Archivo de la Congregación de Propaganda Fide, ahora es la Congregación para la Evangelización de los Pueblos, Roma); AJS (Archivo Histórico de San Ignacio, Compañía de Jesús, Santiago), ASS (Archivo de los Salesianos de Don Bosco, Santiago), ASV (Archivo Secreto Vaticano, Ciudad del Vaticano; Arch. Nunz. Cile: Archivo de la Nunciatura Apostólica de Chile; Segr. Stato: Archivo de la Secretaría de Estado; Ep. ad. Princ.: Archivo Epistolae ad Principes); S.RR.SS. (Secretaría de Estado, Sección para las Relaciones con los Estados, Archivo Histórico, Ciudad del Vaticano); AA.EE.SS. (Archivo de la Congregación para los Negocios Eclesiásticos Extraordinarios, Ciudad del Vaticano); entre [ ] el número de la publicación). Abreviaturas: Cfr.: confrontar;
} 
junio de $1912^{1}$, dirigida a los Arzobispos y Obispos de las Iglesias de América Latina y emanada en favor de los pueblos indígenas del continente latinoamericano, para su evangelización y bienestar, y para su defensa y protección. El año pasado se ha cumplido el centenario de esta encíclica.

El presente artículo tiene su origen en una investigación sobre las fuentes manuscritas inéditas de origen chileno de la encíclica. Estas se hallan custodiadas en el Archivo Secreto Vaticano (Ciudad del Vaticano), en el fondo relativo a los documentos del entonces Internuncio Apostólico en Chile, Monseñor Enrico Sibilia, Arzobispo Titular de Side, junto a la correspondencia entre la Santa Sede y el mismo Representante Pontificio ${ }^{2}$.

Se trata de un estudio de historia de la Iglesia cuyas fuentes van desde los años 1907 a 1912 y consideran los territorios chilenos que van desde el río Biobío a Magallanes, incluyendo también la Isla de Pascua ${ }^{3}$. Por

f., ff.: foja, fojas; fr.: fray; ms.: manuscrito; P., p.: padre (sacerdote); r.: recto; S.V.: Señoría Vuestra; v.: verso. Si las fojas citadas no se señalan con «r.»o «v.» significa que están escritas, solamente en «recto». Cuando el caso lo requiere se cita entre [ ] la indicación archivística del texto que queda en manos del remitente. La trascripción de los documentos no ha sido modernizada. A veces se han traducido los textos al español para volver más inmediata la lectura. Con referencia a los nombres propios de las etnias indígenas citadas, se suele usar la terminología que aparece en los documentos, sin por ello excluir el uso propio entre los nativos.

1 AAS, 4 (1912), 521-525; ASV, Ep. Ad. Princ., Positiones et minutae 159, fasc. 55, ff. 1r-6r: encíclica Lacrimabili Statu Indorum, texto final impreso y firmado por Pío X. Con referencia a la redacción de la Lacrimabili statu Indorum, en el ASV se conservan sus borradores: ASV, Ep. ad. Princ., Positiones et minutae, 159, fasc. 55, ff. 7r-49r: redacciones anteriores a la publicación. En Chile el texto aparece en latín en el Boletín Eclesiástico, XVIII (1911-1913), Santiago, 514-517 y en español en La Revista Católica, 16 (núm. 365, 1916), Santiago, 563-566.

2 También se ha investigado en otros archivos vaticanos y chilenos, pertenecientes a las Provincias de las Órdenes y Congregaciones religiosas de los misioneros, archivos ya mencionados en «Siglas». En Santiago, se ha incursionado también en el Archivo Arzobispal y en el Archivo Nacional: estos últimos con referencia a las relaciones entre el Arzobispado y la Internunciatura, y a las relaciones anuales enviadas por los misioneros al Gobierno, aunque no se han hallado informaciones de mayor relevancia.

3 En estos territorios, por un lado, aún no se ha enraizado el anuncio evangélico y la organización eclesiástica se halla en vía de consolidación y, por otro lado, viven pueblos indígenas aún no totalmente evangelizados o en vía de evangelización. Se trata de territorios que se encuentran bajo la jurisdicción de la Internunciatura de Chile. 
ello han quedado fuera de nuestro objeto de estudio las condiciones globales del panorama eclesiástico chileno en fechas anteriores a 1900, ya que los autores de los documentos nos hablan de su experiencia directa, recogida en la primera década del siglo XX, con referencia a las poblaciones aborígenes del país.

De nuestro marco de estudio también quedan afuera consideraciones pertenecientes al ámbito de la misionología de la época, o sucesiva al Concilio Ecuménico Vaticano II, a disciplinas como la etnología y la antropología de los pueblos indígenas citados en los documentos, y a los efectos que la encíclica haya podido tener sobre las gestiones posteriores de la Iglesia chilena y de otros actores institucionales y/o sociales, en todo cuanto dice relación con la situación de los indígenas, como por ejemplo el Congreso Araucano presidido por el Arzobispo de Santiago en 19164;

Esta recibe de la Sagrada Congregación de Propaganda Fide las facultades canónicas necesarias en favor de los Vicariatos y Prefecturas apostólicas. Sobre el tema: ASV, Arch. Nunz. Cile, fasc. 42: Titolo VI, rubrica II, sezione 1a: Dipendenza dei Vicariati e delle Prefetture apostoliche dall'Internunziatura. Además de los territorios en el sur del país, también en el norte Propaganda Fide extiende su jurisdicción, como en el caso del Vicariato Apostólico de Antofagasta «en fuerza de la Constitución Apostólica Sapienti Consilio»: ASV, Arch. Nunz. Cile, fasc. 42, f. 5r; sin embargo, no se piden relaciones desde Antofagasta porque se dice que ya no hay propiamente indígenas, sino mestizos, que hablan castellano y son católicos: Cfr. las anotaciones en ASV, Arch. Nunz. Cile, fasc. 38, f. 60. Se vea también lo afirmado por el arzobispo de Santiago en carta dirigida al Internuncio (Santiago, 6 de agosto de 1912), en la que el prelado chileno escribe que «en esta Arquidiócesis no existe un solo indígena, la evangelización y defensa de los que moran en el territorio de las diócesis australes de la República será uno de los puntos que han de tratarse en la próxima reunión de los obispos de esta provincia eclesiástica»: ASV, Arch. Nunz. Cile, fasc. 38, f. 177.

4 Cfr. AArS, Legajo 66 N 12, Congreso Araucanista. Sobre su celebración en Santiago (1916); ff. 1-9. Publicado también en La Revista Católica, 16 (núm. 365, 1916), Santiago, 560-572. Al final de su encíclica el Papa reclama la colaboración entre los Gobiernos de los Estados latinoamericanos y la Iglesia («si a la labor del gobierno se uniese la de la Iglesia, entonces ciertamente se obtendrían muchísimo mejores frutos»), y recuerda a los Prelados del continente su oficio de Pastores («a fin de que aportéis cuidados y resoluciones peculiares a esta causa, que pertenece a lo más digno de vuestro pastoral oficio y cargo, y dejando de lado las demás cosas de vuestra solicitud e industria, os exhortamos encarecidamente ante todo, que todas aquellas cosas que en vuestra diócesis están instituidas para el bien de los indios, la promováis con toda vuestra preocupación, y al mismo tiempo cuidéis de instituir aquellas otras que parezcan necesarias a la misma causa»). Recordamos finalmente que en Santiago se había fundado por iniciativa de Isabel Correa de Irarrázaval la «Sociedad Protectora de Indígenas del Sagrado Corazón» con la aprobación del Arzobispo de Santiago, 
temas, estos, que quedan abiertos para futuras investigaciones históricas y/o interdisciplinarias.

El artículo se estructura lógicamente en los siguientes puntos: presentación del material documental inédito que constituye las fuentes chilenas de la encíclica Lacrimabili statu Indorum y de la correspondencia entre la Santa Sede y el Internuncio en Chile; las informaciones acerca de los hechos del Putumayo (Amazonía) y la fase investigativa requerida por la Santa Sede a sus Representantes diplomáticos en América Latina; el informe de los misioneros capuchinos de la Prefectura Apostólica de la Araucanía; las informaciones del Internuncio Monseñor Enrico Sibilia y las primeras instrucciones de la Santa Sede; conclusiones.

\section{LAS FUENTES CHILENAS DE LA ENCÍCLICA «LACRIMABILI STATU INDORUM»}

En el fascículo 38 del fondo Archivio della Nunziatura del Cile del Archivo Secreto Vaticano ${ }^{5}$ he hallado los originales inéditos de los informes que constituyen las fuentes chilenas de la encíclica de Pío X.

El título del fascículo, que entonces era parte del archivo del primer Internuncio, es «Evangelizzazione degli Indiani esistenti in Cile» y los documentos pueden organizarse como a continuación.

A. Informes de los misioneros y evangelizadores:

1) La relación desde la Provincia Franciscana de los Siete Gozos de la Bienaventurada Virgen María ${ }^{6}$, firmada por el franciscano Juan José de Cock$^{7}$, Delegado General, y fechada Chillán, 18 de septiembre de 1911;

Mariano Casanova, y de los otros obispos sufragáneos. En la petición que Casanova dirige a Pío X en 1905, para que el Papa otorgue a los miembros de la Sociedad las indulgencias que estime oportunas, se describe el fin que persigue: «objeto de conseguir la conversión y civilizada educación de los infieles, en especial de los Araucanos»: Fernando Retamal, Chilensia Pontificia, II/2, Santiago: Ediciones Universidad Católica 2002, 1063. Véase también los documentos relativos a la citada «Sociedad» en AA.EE.SS., Posizione 373, fasc. 84, Santiago 1905.

5 ASV, Arch. Nunz. Cile, fasc. 38.

6 ASV, Arch. Nunz. Cile, fasc. 38, ff. 30r-33v.

7 Véase: «Fr. Juan José de Cock Beyaert», en Hugo Araya, Notas Biográficas de Religiosos Franciscanos de Chile, Santiago, Alfabeta Impresores 1976, 128-129. Véase también: Rigoberto A. IturRiaga, 4.268 nombres y otros datos... Elenco de 
2) La relación desde la Prefectura Apostólica de la Araucanía ${ }^{8}$, relación encomendada al misionero capuchino Atanasio de Eglsee? fechada en Valdivia, 10 de octubre de 1911;

3) La relación acerca de los indios aún llamados chonos ${ }^{10}$ del jesuita Silvestre Antonio Correa Bravo ${ }^{11}$, quien la escribe y la firma; la fecha es Santiago, 22 de agosto de 1912 ${ }^{12}$;

4) La relación desde la Prefectura Apostólica de la Patagonia Meridional ${ }^{13}$ es firmada por el salesiano José Fagnano ${ }^{14}$, Prefecto, con fecha en Punta Arenas, 19 de octubre de 1911;

5) Algunos documentos diferentes sobre la Isla de Pascua, Rapa Nui, y sus habitantes, los Rapa Nui (a los que, en los textos, se les identifica

religiosos de la Orden Franciscana que han pasado por Chile, Santiago, Publicaciones del Archivo Franciscano [100], 2001, 125.

8 ASV, Arch. Nunz. Cile, fasc. 38, ff. 41r-52v.

9 Véase: Sergio Uribe, Necrologio de la Provincia Capuchina de San Francisco de Asís en Chile, ms., Archivo de la Provincia Capuchina de Chile, Santiago de Chile. Véase también: Analecta Ordinis Minorum Capuccinorum, núm. 61 (1945), Roma, col. 78; Lexicon Capuccinum. Promptuarium Historicum-Bibliographicum Ordinis Fratrum Minorum Capuccinorum, 1525-1950, Romae, Bibliotheca Collegii Internationalis S. Laurentii Brundusini 1951, col. 143; Arellano, op. cit., 481.

10 ASV, Arch. Nunz. Cile, fasc. 38, ff. 54-55 y ff. 56-57 (estás últimas contienen el mismo texto pero escrito a máquina). Las informaciones y sugerencias que Sibilia envía a la Santa Sede (11 de febrero de 1912, N. 147) sobre los chonos, coinciden con las que le dará sucesivamente Correa, pero probablemente las recibió del obispo de Ancud Ramón Ángel Jara Ruz, predecesor de Valenzuela Poblete en ese obispado hasta diciembre de 1911, tal como dice en la citada relación N. 147: ASV, Arch. Nunz. Cile, fasc. 38, f. 111.

11 En AJS en la carpeta personal relativa a Silvestre Antonio Correa Bravo se hallan diferentes papeles con las noticia biográficas. Véase también: AJS, Iribarne, Juan, 308, carpeta 14; Catalogo Defunctorum in renata Societate Iesu ab a. 1814 ad a. 1970, Romae, Apud Curiam P. Gen., 1972, 256.

12 El documento no tiene anotado el lugar de donde se escribe; considerando el membrete de la foja que Correa usa para escribir al Internuncio ( $J$ JS Colegio de San Ignacio. Santiago. Chile») y las fechas de las dos cartas de agradecimiento por la ayuda a los enfermos de Río Bueno a inicio de 1912 contenidas en su carpeta personal, se puede suponer que Correa responda al Internuncio desde la capital.

13 ASV, Arch. Nunz. Cile, fasc. 38, ff. 58r-58v y 74r-74v.

14 Véase: Pietro Stella, «Fagnano, Giuseppe», en Dizionario Biografico degli Italiani, 44, Roma, Società Grafica Romana, 1994, 192-196. 
generalmente como Canacas) ${ }^{15}$ : el Informe del presbítero Zósimo Valenzuela, capellán de la Vicaría Castrense, acerca de su viaje y estadía en la isla desde el 25 de marzo al 13 de abril de $1911^{16}$; un artículo del diario El Mercurio (30 de agosto de 1911) y otro de $L a$ Unión (17 de junio de 1912); apuntes del Internuncio y de otras manos (dos fojas, sin firma pero con fecha Santiago 5 de septiembre de 1911, tienen el membrete de la Vicaría Castrense y hacen referencia a la misión de Valenzuela, sintetizando los datos: ff. 84-85).

B. La minuta de la relación que el Internuncio en Chile monseñor Enrico Sibilia ${ }^{17}$ ha enviado el 11 de febrero de 1912 a la Secretaria de Estado a servicio de la Santa Sede ${ }^{18}$.

C. Los despachos que la Santa Sede ha enviado a sus Representantes Pontificios en América Latina, y específicamente al Internuncio en Chile el 22 de mayo de $1911^{19}$ y el 9 de abril de $1912^{20}$.

Se trata pues, de un material documental casi totalmente escrito en español (los despachos desde Roma y la minuta de Sibilia están escritos en italiano) y de diferente naturaleza, extensión, composición y contenido; el título del fascículo aclara la temática que da unidad al cuerpo documental. En su gran mayoría el fascículo contiene hojas manuscritas (despachos, informes, minutas), sin embargo hallamos también algunos

15 ASV, Arch. Nunz. Cile, fasc. 38, ff. 78-86.

16 Zósimo Valezuela, La Isla de Pascua, Santiago, Imprenta de San José, 1912. Véase: "Valenzuela Zocimo»: Raymundo Arancibia, Diccionario biográfico del clero secular chileno. 1918-1969, Santiago, Editorial Neupert, 1969, 207.

17 Véase: «Sibilia Enrico»: I «Fogli Udienza» del Cardinale Eugenio Pacelli Segretario di Stato, I (1930), Sergio Pagano, et alii, Città del Vaticano, Archivio Segreto Vaticano, 2010, 487. Véase también: La Gerarchia Cattolica. 1911, Roma, Tipografia Poliglotta Vaticana, 1911, 495; Salvatore Sibilia, Il Cardinale Enrico Sibilia. Un dipomatico della Santa Sede (1861-1948), Roma, Tipografia della Pace, 1960; Angelo Sodano, "Los representantes pontificios en Chile y su misión», en La Revista Católica, 87 (núm. 1073, 1987), Santiago, 8-18; Biographisch-bibliographisches Kirchenlexikon, XVII, Hamm-Herzberg-Bautz, 1990, coll. 1292-1293; Hierarchia Catholica medii et recentioris aevi, IX, Patavii, Typis Librariae «Il Messaggero di S. Antonio», 2002, 342. Con referencia a su misión en Chile, el archivo de Sibilia abarca el periodo desde el 29 de diciembre de 1908 al 1 de marzo de 1914.

18 ASV, Arch. Nunz. Cile, fasc. 38, ff. 87-123.

19 ASV, Arch. Nunz. Cile, fasc. 38, ff. 24r-25v.

20 ASV, Arch. Nunz. Cile, fasc. 38, ff. 136r-138v. 
opúsculos, hojas mecanografiadas y recortes de diarios chilenos con las noticias relativas al tema tratado. Los documentos se hallan bien conservados, ordenados y de fácil consultación.

El contexto en el cual se desarrollaban las misiones católicas y en el cual se han escritos los informes halla su breve síntesis en la Crónica del misionero capuchino Burcardo de Röttingen. Conforme a la Constitución de 1833, la labor misionera se desarrolla en un régimen de unión entre el Estado y la Iglesia ${ }^{21}$, régimen que terminará con la ley constitucional de 1925 por medio de la cual se introduce la separación ${ }^{22}$. El fragmento reportado presenta la situación religiosa general a inicio siglo XX y la organización eclesiástica, además de incluir los datos de 1921 y también aquellos relativos al censo de $1907^{23}$ :

«La religión católica es, según la Constitución chilena, religión del Estado. Según la Constitución, solo la religión católica tiene el derecho a practicar públicamente su culto. Solo ella puede tener templos públicos y llamar al culto por medio de campanas. De hecho, sin embargo, reina la más amplia tolerancia, de modo que también otros creyentes tienen sus iglesias y capillas y con campanas y todo, pública y solemnemente, hacen sus funerales por medio de sus ministros de culto. Según el censo de 1907, Chile tenía 3.249.279 habitantes, de los cuales 3.184.072 se declaraban católicos, 2.039 ateos, 24.100 indígenas paganos, 26.166 extranjeros no católicos y 12. 902 chilenos no católicos. En total, habría, pues, 65.207 no católicos. En Chile existen actualmente el arzobispado de Santiago y los obispados de La Serena, Concepción y Ancud. Dentro de poco se erigirán las diócesis de Valparaíso y Talca. Además están los vicariatos apostólicos de Tarapacá y Antofagasta, en el norte, en las provincias conquistadas en la guerra de 1879, y el vicariato apostólico de Magallanes, en Punta Arenas, erigido en 1917. También existe el vicariato Castrense, cuyo prelado es obispo

21 «In republica Chilena lege constitutionali religio catholica adoptata est religio Status (art. 4). [...] Missiones inter Indianos institutae eatenus parco subsidio pecuniario a republica adjuvantur, quatenus eorum pueros in propiis dominus educant»: Theodorus Grentrup, Jus Missionarium, Steyl (Hollandiae), Typographia donum Missionum a S. Michaele Archang. nuncupatae, 1925, 356.

22 Carlos Salinas, "Relaciones Iglesia-Estado», en Historia de la Iglesia en Chile. Los nuevos caminos: la Iglesia y el Estado, Marcial Sánchez (coord.), III, Santiago, Editorial Universitaria, 2011, 231-277.

23 Censo de la República de Chile. Levantado el 28 de noviembre de 1907, Santiago, Sociedad «Imprenta y Litografia Universo», 1908. 
titular y cuya jurisdicción no se extiende solo a Ejército y Marina sino también a los departamentos de Tacna y Arica, cuyos habitantes chilenos han sido todos declarados pertenecientes a las Fuerzas Armadas. Finalmente está la Prefectura Apostólica de Araucanía, confiada por la Iglesia y el Estado a los capuchinos bávaros» ${ }^{24}$.

\section{Las noticias acerca del Putumayo y las indicaciones de la Santa SEDE}

A partir del inicio del siglo XX el Papa Pío $\mathrm{X}^{25}$ inaugura una nueva etapa misionera dando un impulso a su acción y organización. Según

24 ACS, 25 años de actividad misional de los Misioneros Capuchinos Bávaros en la Misión Araucana de Chile. 1896-1921. (Parte primera). Relación preparada para el Archivo por el P. Burcardo M. de Roettingen, O. Cap. Prefecto Apostólico y Superior Regular, traducido por Alfonso Tolose del texto original alemán, I/1, 40. Es oportuno señalar que algunos datos son posteriores a 1912, como se puede observar. Para más informaciones sobre el contexto civil, eclesiástico y eclesial chileno de los primeros decenios del siglo XX véase: Fernando Aliaga, "Historia de la Iglesia en Chile en el período 1914-1939", en Historia de la Iglesia de los orígenes a nuestros días, Guerra mundial y Estados Totalitarios, GeOrges Jarlos (coord.), XXVI/2, Valencia, EDICEP, 1980, 637-665; Canonizationis Servi Dei Alberti Hurtado Cruchaga. (I. Vida y actividad - II. Documentos), Roma 1987; Sergio Villalobos, et alii, Historia de Chile, [19741] Santiago, Editorial Universitaria, 2005; Gonzalo Vial, Historia de Chile (1891-1973). La sociedad chilena en el cambio de siglo (1891-1920), I-2, Santiago, Zig-Zag, 2006; Gabriel Salazar - Julio Pinto, Historia contemporánea de Chile II. Actores, identidad y movimiento, Santiago, LOM ediciones, 2010; Mateo Martinic, "Chile (y Magallanes) entre el centenario y el bicentenario", en Grandes Chilenos del Bicentenario, Santiago, Secretaria Ejecutiva, Comisión Asesora Presidencial Bicentenario, 2010, 117-130; Patricio Valdivieso, Dignidad humana y justicia. La Historia de Chile, la Politica Social y el Cristianismo. 18801920, Santiago, Ediciones Universidad Católica de Chile, 2006.

25 Giuseppe Melchiorre Sarto, Patriarca de Venecia, es elegido Papa el 4 de agosto de 1903 y gobierna la Iglesia hasta el 20 de agosto de 1914. Beatificado el 3 de junio de 1951 y canonizado el 29 de mayo de 1954: Congregatio de Causis Sanctorum, Index ac Status Causarum, Città del Vaticano, Tipografia Guerra, 1999, 578. Las referencias bibliograficas esenciales en: Pio X. Un papa e il suo tempo, Gianpaolo Romanato (coord.), Cinisello Balsamo (Milano), Edizioni Paoline, 1987; Roger Aubert, "Pío X, el papa de la reforma conservadora», en Hubert Jedin, Manual de historia de la Iglesia, VIII, Barcelona, Herder, 1988; Gianpaolo Romanato, Pio X. La vita di Papa Sarto, Milano, Rusconi 1992; Maurilio Guasco, «Pius X», en The Papacy. An Enciclopedia, Philippe Levillain (coord.), II, New York-London, Ed. Routledge, 1994, 1197-1199; Juan M. LabOA, Historia de la Iglesia Católica, V, Madrid, BAC, 1999; Jean-Marc Ticchi, Aux frontières de la paix. Bons offices, 
Butturini se trata de una «relación diferente con los pueblos y con las respectivas culturas y la reorganización de las misiones caracterizan pues al pontificado de Pío X; en este sentido van la creación de más de cincuenta nuevas circunscripciones eclesiásticas (30 prefecturas apostólicas, 18 vicariatos, 6 diócesis) y el ingreso en misión de numerosas nuevas congregaciones religiosas, masculinas y femeninas» ${ }^{26}$.

En esta dirección en 1907 la Congregación de Propaganda Fide crea tres nuevas prefecturas en el territorio del Perú. Una, en la Amazonía, es la Prefectura Apostólica de Ucayali, confiada a los franciscanos ${ }^{27}$. P. Agostino M. Alemany, prefecto apostólico, en carta de 4 de octubre de 1910 dirigida a Propaganda Fide, cuyo secretario es el Cardenal Girolamo M. Gotti, da noticia de los eventos que ocurren en el territorio de su prefectura (precisamente en el Putumayo), como ha sido expuesto por Turvasi ${ }^{28}$. He aquí un fragmento del texto enviado a Roma:

médiations, arbitrages du Saint-Siège (1878-1922), Rome, École française de Rome, 2002; Pio X e il suo tempo, Gianni La Bella (coord.), Bologna, Il Mulino, 2003; Battista Mondin, Nuovo dizionario enciclopedico dei Papi, Roma, Città Nuova, 2006. A propósito de su persona e índole de su pontificado: «Toda la documentación que hasta ahora hemos acumulado debería probar que Giuseppe Sarto no era de ninguna manera un pobre párroco del campo. Capacidad de gobierno, conocimiento de los hombres, experiencia de la Iglesia, pericia en los problemas, seguridad de cultura (cultura vivida, más que meditada en biblioteca), hacían sin duda de él una de las figuras más altas del episcopado del tiempo, aunque poco conocida al público. [...] Él llevaba en el pontificado una experiencia que ningún otro Papa, antes y después de él, pudo tener. La experiencia de la vida concreta, de base, de las parroquias y de los seminarios»: G. Romanato, Pio X. La vita di Papa Sarto, 230, 231, 245.

26 Giuseppe Butturini, «La Santa Sede e i popoli extraeuropei», en Pio X. Un papa e il suo tempo, op. cit., 256.

27 Storia della Chiesa. Dalle missioni alle Chiese locali (1846-1965), Josef Metzler (coord.), XXIV (edición italiana), Cinisello Balsamo: Edizioni San Paolo 1990, 573.

28 Me remito en esta parte a los estudios de: Francesco Turvasi, Giovanni Genocchi and the indians of South America (1911-1913), Editrice Pontifica Università Gregoriana, Roma, 1988, 1-4; Vincenzo Ceresi, Padre Genocchi, Città del Vaticano, Tipografia Poliglotta Vaticana, 1934, 437-468. Las relaciones de los misioneros que a continuación se analizarán, no forman parte del estudio de Turvasi, ni de otros; Turvasi desarrolla su estudio siguiendo los pasos de P. Genocchi y de este último vienen las informaciones usadas por Turvasi. Recientemente se ha lamentado la escasa recepción que la encíclica ha tenido y se ha escrito acerca de la misión de Genocchi: Claudio Bonizzi, "La visita apostolica in America Latina di Giovanni Genocchi», en Rassegna di Teologia, 53 (2012), Facoltà Teologica di Napoli, 299-305. Sin embargo la Iglesia en Colombia ha celebrado un encuentro para el centenario 
«La extracción del caucho en el interior de las selvas existe sobre todo en las regiones del Perú desde el siglo pasado. [...] Los civilizados han puesto su corazón con agudeza de ingenio en iniciar y continuar un negocio que en los estados europeos era considerado de gran importancia. Pero la obra de extracción del caucho lograba poco resultado a menos que los paganos nativos, quienes conocen perfectamente aquellas regiones y su topografía, sean utilizados en la operación. Por ello los interesados en la extracción del caucho, considerando necesario que se les entregara en un número suficiente a los indígenas, los compraron de otros colonos, que consideraron siempre lícito vender o transferir a los indígenas, aun cuando al hacer esto actúan de manera injusta. Los extractores de caucho envían a sus emisarios, para que vayan en las zonas donde moran los infieles, y allí los asaltan con armas de guerra, queman y destruyen sus hogares, capturan a los niños y a las mujeres indefensas, matan a los viejos, luchan contra los hombres que intentan defenderse a sí mismos, a sus familias y a la tierra que no quieren abandonar, los asesinan o los llevan presos a los lugares de extracción, donde bajo una severa vigilancia y una rigurosa disciplina, por un periodo de muchos años y a menudo por toda la vida, recolectan, ordenan, llevan y transportan la mercancía ya mencionada de

de la encíclica (Bogotá, 18-20 de septiembre de 2012) y el Papa Benedicto XVI el 15 de junio de 2012 ha enviado un mensaje recordando la encíclica de su predecesor (texto en http://www.vatican.va/holy_father/benedict_xvi/messages/ pont-messages/2012/documents/hf_ben-xvi_mes_20120615_bogota_it.html). La historiografía de los últimos decenios, no ha considerado el aspecto misional del pontificado de Pío X. En 1987 Butturini, a propósito de las relaciones de la Santa Sede con los países extraeuropeos, escribía que «en la historiografía eclesiástica más reciente el rol desarrollado por Pío X en el campo de las relaciones con los pueblos extraeuropeos o más en general con el mundo misionero no se resalta y a veces ni siquiera es recordado; es necesario remontar a las obras de Schmidlin o de Delacroix para darse cuenta que algunas de las elecciones más características de los papas Benedicto XV y Pío XI habían sido ya entrevistas, si no predispuestas, bajo el pontificado piano»: G. ButTurini, "La Santa Sede e i popoli extraeuropei», en Pio $X$... 253-254. Schmidlin afirmaba: «Las misiones sudamericanas e Indígenas, hallaron no menos cariñoso hacia ellas, a un jefe de la iglesia protector y promotor solicito. Él solemnemente en su carta circular del 7 julio [sic] de 1912 a todo el episcopado de América Latina levantó su voz dolida en favor de los indígenas del Putumayo contra los horrores comparables solo con las locuras paganas»: Josef Schmiduin, Papsgeschichte der neusten Zeit, III (Pius X. und Benedikt XV. 1903-1922), München, Verlag Josef Kösel \& Friedrich Pustet, 1936, 137. Más recientemente Gianni La Bella ha afirmado que «contrariamente a cuanto hasta ahora se ha pensado, América Latina constituyó, desde el inicio, una de las constantes preocupaciones del magisterio papal y una de las prioridades de la Santa Sede»: «Pio X e l'America Latina», en Pio X e il suo tempo, Gianni La Bella (coord.), Bologna, Il Mulino, 2003, 641. 
un lugar a otro. [...] Cuando un colono se ha vuelto rico, no duda en venderlos a otro comercio, y así la vida de los pobres infieles resulta del todo parecida a la de un esclavo, porque no brilla la esperanza de volver a ver a sus queridos o de regresar a los lugares de la propia región» ${ }^{29}$.

Informado de estos acontecimientos el Papa Pío X manda que se interpelen los Representantes Pontificios en América Latina para tener precisas informaciones y nombra como su visitador al P. Giovanni Genocchi, religioso del Sagrado Corazón de Jesús ${ }^{30}$. Desde Roma el Secretario de Estado, Cardenal Rafael Marry del Val, escribe a los Nuncios e Internuncios presentes en el continente latinoamericano ${ }^{31}$. El 22 de mayo de 1911 escribe al Internuncio en $\mathrm{Chile}^{32}$, monseñor Enrico Sibilia, dependiente de la Nunciatura de Lima ${ }^{33}$. He aquí el texto del despacho:

29 APF, Perú, Ucayali, R. 151.299, ff. 478r-478v (fojas desde 478r a 481v) [texto original en latín]. El escrito, tal como se ve anotado con lápiz de mina en la f. $481 \mathrm{v}$, se relaciona a otro de Alemany enviado por medio del superior de la Orden a Propaganda Fide, siempre con objeto la situación en su prefectura cuyo título es Status Praefecturae Apostolicae S. Francisci de Ucayali in Peruvia: APF, Perú, Ucayali, R. 151.2438, ff. 478r-481v.

30 «La misión pontificia confiada al P. Genocchi en julio de 1911 tenía un doble objetivo: referir a la Santa Sede acerca del estado actual de los indígenas de América latina en vista de su evangelización, y más concreto y urgente entrar, con la obra, en la gran cuestión del Putumayo, que en aquellos días conmovía a dos continentes y comprometía juntamente el honor de la civilización y de la religión»: V. CERESI, Padre Genocchi..., 437. La situación de explotación e injusticia, esclavitud y asesinatos, había además trascendido el Perú y se había impuesto a la atención internacional: F. Turvasi, Giovanni Genocchi and the indians of South America..., 61.

31 Cfr. ASV, Segr. Stato, año 1913, rubr. 17, fasc. 4, ff. 9r-10v [se trata de la minuta que permanece en ASV, Segr. Stato]; en la f. 9r hallamos que esta "Circolare» (o despacho) nombrada "Evangelizzazione degli Indiani nell'America Latina» se envía el 22 de mayo de 1911 a «Mgr. Enrico Sibilia Internunzio Apostólico, Santiago (Chile)», el 24 de mayo de 1911 a «Mgr. Achille Locatelli, Internunzio Apostólico, Buenos Aires (Argentina), el 27 de mayo de 1911 a «Mgr. Angelo G. Scapardini, Delegato apostolico per il Peru, l'Equatore e la Bolivia, Lima (Perú)», el 7 de junio de 1911 a «Mgr. Francesco Ragonesi, Delegato Apostolico, Bogotá (Colombia)», el 7 de junio de 1911 a «Mgr. Giovanni Battista Cagliero, Delegato Apostolico, San José de Costa Rica (Costa Rica)». Sobre las Nunciaturas e Internunciaturas Pontificias de ese entonces véase: Giuseppe de Marchi, Le Nunziature Apostoliche dal 1800 al 1956, I, Città del Vaticano, Libreria Edictrice Vaticana, 2006.

32 ASV, Arch. Nunz. Cile, fasc. 38, ff. 24r-25v.

33 Con referencia a Chile: creada bajo el pontificado de León XIII la Delegación Apostólica y nombrado el 15 de enero de 1903 al Delegado Apostólico y Legado 
[f. 24r] [Membrete] Segreteria di Stato di Sua Santità

N 50691

Dal Vaticano, 22 Maggio 1911

[en lápiz de mina, arriba] Ric. 13 Luglio 1911

Ill.mo e Rev.mo Signore

Non ignora la S.V. Rev.ma il triste stato in cui trovansi molte popolazioni indigene negli estesissimi territori centrali dell'America Latina, prive ancora della luce del Vangelo, non ostante i molti provvedimenti che si sono presi e si prendono di continuo per l'incremento e l'espansione della Chiesa in coteste Repubbliche. L'infelice stato di tante anime immerse nelle tenebre dell'ignoranza e dell'errore non può non impressionare vivamente l'animo del Santo Padre, il Quale intende che i Rappresentanti Pontifici nell'America Latina volgano ad un oggetto sì grave il loro studio e la loro solle [f. 24v] citudine.

Allo scopo pertanto di mettere la Santa Sede in grado di prendere provvedimenti utili a conseguire il Santo fine di procurare, per quanto sarà possibile, il beneficio della vera fede a quelle anime, interesso d'ordine di Sua Santità, la S.V. a raccogliere tutte quelle notizie ed indicazioni che le sarà dato procurarsi intorno a questo importante argomento, e farne poi una estesa relazione alla Santa Sede.

Extraordinario en la persona de monseñor Pietro Monti (Cfr. F. Retamal, Chilensia Pontificia, II/2 978-983), Pío X la eleva al rango de Internunciatura Apostólica, confiando el 1 de octubre de 1908 el cargo de Internuncio a monseñor Enrico Sibilia (Cfr. F. Retamal, Chilensia Pontificia, II/3, 2005, 1144-1147). Este, entregadas sus credenciales al Presidente de la República el 29 de diciembre de 1908, desde su sede en Santiago se dirige al episcopado chileno con estas palabras: «Enviado por el Pastor supremo, llego hasta vosotros ofreciéndome como compañero vuestro en los trabajos, ayuda en las dificultades y defensor en las diversas circunstancias de la vida: esta es mi tarea, este es mi propósito» («Internunziatura Apostólica», en F. Retamal, Chilensia Pontificia, II/3 1147). El periodo de Sibilia resultó difícil debido a la situación política y a diferentes problemáticas eclesiásticas que afectaron las buenas relaciones del inicio (Cfr.: Ricardo Donoso, «La misión Sibilia», en Anales de la Facultad de Teología, 33 (1982), Santiago, 229-269; Fidel Araneda, Historia de la Iglesia en Chile, Santiago, Ediciones Paulinas, 1986, 625-627, 672-674; Juan I. González, El Arzobispo del Centenario. Juan Ignacio González Eyzaguirre, Santiago, Centro de Estudios del Bicentenario, 2003, 78-113; Gonzalo Vial, Historia de Chile (1891-1973). La sociedad chilena en el cambio de siglo (1891-1920), I-1, op. cit., 2006, 290-291; GonZalo VIaL, Historia de Chile (1891-1973). Triunfo y decadencia de la Oligarquia (1891-1920), II, op. cit., 2008, 498 y 571). 
Avrà quindi cura la S.V. di riferire anzitutto su quel che già si è potuto ottenere colle Missioni fra gl'Indiano che trovasi nei limiti della sua Delegazione, notando quanti e di quale importanza siano gli Istituti Missionari in essa esi [f. 25r] stenti.

Ma principalmente Ella cercherà di trasmettere informazioni geografiche ed etnologiche, quanto più potrà esatte, su territori ai quali non ancora si estende l'attività delle Diocesi e Missioni di cotesta Repubblica, sul numero e sul carattere dei selvaggi ivi sparsi, sui loro centri principali, sulle vie di comunicazione e sulle difficoltà che possono opporsi alla loro evangelizzazione.

Non tralascerà poi di dire quali, a suo giudizio, potrebbero essere le eventuali disposizioni di cotesto Governo al riguardo, e quale concorso potrebbe sperarsi da parte del medesimo ad un'opera di sì alto interesse religioso insieme e civile.

Finalmente [f. 25v] la S.V. dopo aver interrogato all'uopo persone autorevoli ed esperte, non mancherà di comunicare alla Santa Sede tutti quei suggerimenti che, insieme alla accennate notizie ed al suo saggio parere in proposito, potrebbero servire come di base per uno studio concreto sul modo d'iniziare e promuovere un'impresa si tanta importanza.

Con sensi di ben sincera stima mi raffermo di V.S.R.

Aff.mo per servirla

\section{R. Card. Merry del Val}

[en la parte abajo] Mgr. Enrico Sibilia, Internunzio Apostolico, Santiago

El objetivo que la Santa Sede persigue por medio de sus diplomáticos es considerada una acción apostólica y humanitaria ${ }^{34}$ específicamente dirigida hacia personas y pueblos no cristianos: recoger las informaciones inherentes a los pueblos indígenas del continente aún no evangelizados, para iniciar un estudio de la situación, del cual podrán surgir las directrices a las Iglesias locales y a los misioneros para su trabajo apostólico y para la defensa de los indígenas, esperando actuar en colaboración con

34 «Opera più apostolica e più umanitaria credo che Sua Santità non potrà certo compiere durante il Suo pontificato: sono tante e tali le atrocità che si commettono in quelle lontane ed abbandonate regioni amazzoniche»: David Quattrocchi (Encargado de "Affari Inter. della S. S.») al Cardenal Merry del Val en carta desde Lima, 23 de agosto de 1911: ASV, Segr. Stato, 1913, rubr. 17, fasc. 4, f. 47. 
el Gobierno del país. Una vez recibidas las instrucciones, el Internuncio Sibilia se dirige a los Superiores religiosos interesados, pidiéndoles las informaciones requeridas ${ }^{35}$.

\section{La relación desde la Prefectura Apostólica de la Araucanía}

La tarea de redactar el informe ha sido encomendada al misionero capuchino Atanasio de Eglsee, quien, como dicho, escribe desde Valdivia el 10 de octubre de $1911^{36}$. Prefecto Apostólico de la Araucanía es el capuchino Burcardo de Röttingen ${ }^{37}$.

35 «Mgr. Internunzio ha chiesto informazioni esatte ai capi delle Missioni esistenti»: P. Genocchi al Cardenal Merry del Val en carta desde Lima, 17 de septiembre de 1911: ASV, Segr. Stato, 1913, rubr. 17, fasc. 4, f. $56 v$.

36 Como para los otros informes, el Internuncio confirma haber recibido esta relación (carta fechada en Santiago, 15 de noviembre de 1911: ASV, Arch. Nunz. Cile, fasc. 38, ff. 53r). Copia de la relación enviada por de Eglsee la hemos encontrado en la llamada Crónica de Burcardo de Röttingen, en idioma español: ACS, 25 años de actividad misional de los Misioneros Capuchinos Bávaros en la Misión Araucana de Chile. 1896-1921. (Parte primera). Relación preparada para el Archivo por el P. Burcardo M. de Roettingen, O. Cap. Prefecto Apostólico y Superior Regular, traducido por Alfonso Tolose del texto original alemán, I/1, 30-36 [texto inédito mecanografiado]. En el original alemán: ACS, Fünfundzwanzigjährige Missionstätigkeit der bayerischen Kapuzinermissionäre in der Araukaniscen Mission Chiles, von 1896-1921, Zuzammengestellt für das Archiv von Burchard, P. M. von Röttingen, O. Cap., Apostolischer Präfekt und Regularoberer, I, 39-48 [texto inédito mecanografiado]. El texto de Röttingen es ligeramente diferente al manuscrito original de la relación, debido probablemente a la traducción al alemán de Röttingen y de nuevo al castellano por Alfonso Tolose. Sin embargo, hay que señalar una particularidad en el texto de Röttingen: este atribuye la relación a Félix José de Augusta: «Sobre el estado actual de los indios, el P. Félix José de Augusta escribió, en 1911, a petición del Internuncio Apostólico en Chile, un relato muy interesante» (texto de la traducción española, 30-31). Considerado que Röttingen, hallándose en Alemania mientras redacta su texto, sufre de problemas a la vista y no dispone de todos sus papeles, es posible suponer que haya un error. Finalmente, hay que señalar que Félix José de Augusta y Atanasio de Eglsee son los colaboradores más cercanos del Prefecto Röttingen, que tiene su sede en Valdivia, y donde el P. Félix se encuentra en los meses de julio y agosto de 1911 (Cfr. Carmen Arellano, et alii (eds.), En la Araucanía. El padre Sigifredo de Frauenhäusl y el Parlamento mapuche de Coz Coz de 1907, Madrid-Frankfurt am Main, Vervuert 2006) 347 y puede haber colaborado en la redacción de la relación.

37 Véase: «Burcardo María de Röttingen (Andrés Englert)»: S. URibe, op. cit.. Véase también: Analecta, op. cit., 61 (1945), col. 79; Lexicon Capuccinum, op. cit., col. 280; C. Arellano, En la Araucanía. El padre Sigifredo de Frauenhäusl... 482-483. 
La relación se encuentra escrita por dos manos (la segunda, con la firma, es la de Eglsee). Se trata de la más extensa, articulada y rica en datos y observaciones de las relaciones enviadas al Internuncio; por ello aquí nos centramos en ella presentándola de manera expositiva, siguiendo su

A partir de la segunda mitad del siglo XIX hasta inicio del XX, se asiste a tres llegadas de misioneros capuchinos, por medio de las cuales se busca remediar a la escasez del personal misionero: los italianos, que llegan a Chile en 1848 y empiezan su labor en la Araucanía, los españoles de Castilla (1888-1889) y finalmente los capuchinos bávaros (1896), que dan nuevo impulso a la misión. En 1899, tres años después de haber llegado, ya son quince sacerdotes y ocho hermanos, frente a los últimos siete sacerdotes italianos. El 16 de julio de 1901 la misión capuchina es elevada a Prefectura Apostólica por la Congregación de Propaganda Fide y Röttingen es nombrado Prefecto Apostólico el 30 de julio de 1901 (Cfr. Analecta, op. cit., 17 (1901), col. 228. En 1900, al momento del nombramiento del superior bávaro y del pasaje de la misión en manos de los alemanes, no se encuentra el decreto de erección canónica de la Prefectura: Cfr. Albert Noggler, Cuatrocientos años de misión entre los araucanos, Temuco: Imprenta y Editorial San Francisco 1982, 123-125; Ignacio de Pamplona, op. cit., 505-506. En 1895, por ejemplo, se considera existente la Prefectura con su prefecto: «Valdivia es actualmente la residencia del prefecto apostólico, nombrado por la sagrada congregación de Propaganda Fide»: La Provincia Eclesiástica Chilena, erección de sus obispados $y$ división en parroquias, Friburgo (Alemania): Herder 1895, 217). La presencia de siete parroquias diocesanas en el territorio de la Prefectura Apostólica, genera algunas dificultades de jurisdicción entre esta y la Diócesis de Ancud que afectan negativamente el cuidado pastoral en las parroquias y en las misiones. En 1908 se alcanza un acuerdo en Roma, confirmado por la Congregación de Propaganda Fide y el por Pío X en 1909, que establece las respectivas demarcaciones territoriales y competencias pastorales, sin embargo los problemas no se solucionan de manera definitiva. (Cfr. Prefecturas Apostólicas [Convenio jurisdiccional entre el Obispado de Ancud y la Prefectura Apostólica de la Araucanía, Roma, 21 de junio de 1908 y Demarcación entre las Parroquias y las Misiones de Capuchinos, 2 de agosto de 1909], en F. Retamal, Chilensia Pontificia, II/3, 1148-1153; "En estos tiempos [1909] se había separado el territorio de la Prefectura Apostólica del territorio de la diócesis de Ancud»: Sigifredo de Frauenhäusl, Crónica de la Misión de San Sebastián de Panguipulli. Primer Libro 1904-1924, en C. Arellano, En la Araucanía... 339). Bibliografía esencial acerca de la misión capuchina y el pueblo mapuche en: IGNACiO de Pamplona, Historia de las misiones de los PP. Capuchinos en Chile y Argentina (1849-1911), Santiago, Imprenta Chile, 1911; Horacio Zapater, Esbozo histórico del desarrollo de los pueblos araucanos, Santiago, Universidad Católica de ChileInstituto de Geografía, 1974; Ignacio Domeiko, Mis viajes, Santiago, Ediciones de la Universidad de Chile, 1978; José Bengoa, Historia del pueblo mapuche, Santiago, Ediciones Sur, 1985; Misioneros en la Araucanía, Temuco, Ediciones de la Universidad de la Frontera 1988; Sol Serrano, "De escuela indígenas sin pueblo a pueblo sin escuelas indígenas: la educación en la Araucanía en el siglo 
misma estructura y temáticas, ofreciéndola al lector de manera prácticamente integral.

A continuación los ítems expuestos:

1. topografía;

2. población;

3. caminos de comunicación;

4. costumbres y creencias;

5. ideas religiosas de los indios modernos;

6. número y ubicación de las misiones y personal misionero (o datos estadísticos);

7. causas que impiden hacer más rápida la evangelización;

8. medios usados para la evangelización.

Consideramos ahora el documento.

1. El territorio misional capuchino se sitúa entre los grados 38 1 1/2 y 40 1/2 de latitud austral, en los territorios de la Diócesis de Concepción y de la Gobernación Eclesiástica de Temuco, al norte, y el río Millantue, al sur. Hacia este territorio se tienen también palabras que desvelan lo que hoy se llama una "conciencia ecológica»: «Desde la entera Pacificación de los Indios y la ocupación de su suelo por el Gobierno de Chile, o sea por particulares, se trabaja en todo el territorio febrilmente en la destrucción de los bosques, ya explotándose la madera laborable, ya con el fin de ganar suelo fértil para el cultivo [...] pero al mismo tiempo quedan bárbaramente destruidas las majestuosas selvas con toda su interesante vegetación y el encanto de su misteriosa antigüedad, sin que se haya pensado hasta ahora en una replantación sistemática» (ff. 42r-42v).

XIX», en Historia 29 (1995-1996), Santiago, 423-474; HÉctor CAmpos, 150 años de la Orden Capuchina en Chile, en Analecta, op. cit., 114 (1998), coll. 307-311; LEONARDo LÉON, «Tradición y modernidad: vida cotidiana en la Araucanía (19001935)», en Historia 40/2 (2007), Santiago, 333-378; René Millar, «La Iglesia y la construcción de la República», en Humanitas, 60 (2010), Santiago, 654-675; Gabriel Guarda, "Misiones en el sur. La Iglesia de Valdivia 1820-1925», en Historia de la Iglesia en Chile. Los nuevos caminos..., op. cit., 403-453. 
2. La Prefectura cuenta con «una población de 69.600 chilenos de raza española y de extranjeros, y de 53.600 indios, de los cuales 32.000 son católicos y 21.600 infieles" (f. 42v). Como la gran mayoría de la población, también los indios viven aislados sin embargo se hallan de cuatro a seis chozas unidas o a poca distancia; en todo el territorio hay cuatro pueblos que superan los mil habitantes sin alcanzar a los 2.000 (las casas frente a Temuco; Bajo Imperial; San José en la provincia de Valdivia; San Pablo en la misma provincia). Además -se informa- existen unos nuevos pueblos, cuya población varía entre los 200 y 700 habitantes.

3. Con los caminos principales, en un estado atrasado, las vías de comunicación son el ferrocarril y los vapores fluviales; «los muchos ríos hacen los viajes muy peligrosos, sobre todo en invierno por falta de embarcaciones para el balseo y de puentes. Hay ocasiones en que el Misionero debe pasar ríos sobre el caballo que nada, otras en que un campesino lo carga al hombro para pasar por un pantano» (ff. 43r-43v).

4. Eglsee dedica a este punto varios temas que merecen ser reportados.

a. El temor al pasado y la incertidumbre hacia el futuro: «La causa por qué los indios no quieren juntarse en pueblos no es tanto su amor a la libertad e independencia, como el temor no siempre infundado de perder la vida por las brujerías y los venenos de sus propios compatriotas", sin embargo no tienen opción porque "el modo de conseguir su sustento lo exige, pues hoy día se dedican mayormente al cultivo de los campos, juntamente con la crianza de animales, que ya antiguamente había sido su ocupación» (f. 43v).

b. La migración a la ciudad en busca de empleo: no pocos son los indios que se ven obligados a ir a las ciudades parcial o definitivamente, en busca de un empleo, según los oficios que han aprendido; los empuja la necesidad «la cual cada año, más se irá haciendo sentir; porque el Supremo Gobierno ha dejado la gran mayoría de los indios con una muy exigua extensión de terrenos tocándoles solamente 3-4 hectáreas por cabeza» (ff. 43v-44r).

c. La cuestión de la tierra: «Se le ha radicado en el suelo donde tenían sus casas y se les ha marcado su parte de terreno sin respetar los limpios o roces que habían hecho, ni tomar en cuenta la mala condición de los terrenos. La tierra que ha quedado vacante, la 
habían tomado ya antes los chilenos o extranjeros, unos con algún título de justicia, otros con atropellos y muy descarada astucia, como es conocido, mientras que otra porción de terreno ha sido entregada por el Supremo Gobierno a unas empresas colonizadoras que traían colonos extranjeros, o a lo menos lo prometían, o se ha dado a meritorios servidores del Estado o de partidos políticos dominantes» (f. 44r).

d. El pasado y la injusticia del presente: «En el último alzamiento les quitaron o mataron los soldados millares de animales (en el norte de la Prefectura), con otra parte de animales han concluido los ladrones, pues el abigeato está en voga en grande escala, gracias a la debilidad, ineficacia o culpable connivencia de los juzgados. El indio que roba y es descubierto, paga su iniquidad con presión y flagelos, mientras que el carnicero que compra los animales robados de todas partes está sentado entre los curules o ejercita el cargo de juez» (ff. 44r-44v).

e. La trasformación del indio en agricultores, no sin ser afectados por la pobreza: a partir de la pacificación de la Araucanía, los indios se han trasformado "con asombrosa rapidez en agricultores, y cultivan su suelo al modo que han aprendido de los campesinos chilenos con quienes solían trabajar en común. Hay indios que cosechan una buena cantidad de cereales y que poseen máquinas trilladoras, pero la gran mayoría es pobre y puede solo subsistir por la gran sencillez en su alimentación. Felices son aquellos que viven a orillas del mar o de los lagos donde pueden aprovechar marisco y los peces» (f. 44v).

f. La morada: «La ruca de los indios es una choza de diferente construcción en el norte y en el sur; pues, mientras que en el sur las hacen más al modo de los campesinos chilenos, en el norte las hacen de forma oblonga con apsis en una extremidad y el frente opuesto con dos esquinas» (f. 45r).

g. La alimentación: esta «es casi la misma que la de los campesinos chilenos pobres, a veces tienen carne, otras veces se contentan con papas, maíz, habas, porotos, etc., preparados de muchas maneras. [...] hay no pocos indígenas que poseen casa techada con zinc, se sirven de mesas y sillas y comen como los chilenos. Es mentira que 
los indios comen solamente carne de caballo, ellos comen de todo, en lugar del pan tienen su harina tostada» (f. 46r).

h. Las vestimentas, de ayer y de hoy: «Los hombres muchos se visten hoy día como los chilenos, con gusto y alguna variedad, el traje antiguo viene ya en desuso, que es un chamall: un paño de tejido negro que se pasa entre las piernas y se amarra en el cinturón, debajo otro paño blanco que sirve de calzoncillos, y encima la manta de bonitos colores y admirables dibujos, trabajo de sus mujeres. Estas envuelven todo el cuerpo en un paño llamado Küpam [Rúpam] negro, también trabajo de sus manos, de manera que un brazo queda libre, lo ciñen con un cinturón bordado artísticamente; además una capa larga del mismo tejido que el que envuelve decentemente todo el cuerpo con los hombros, y que ponen luego que se presente algún forastero de cierto respeto. Ahora casi todas las mujeres usan camisa con mangas largas y puños y cuando no la tienen, es solamente por la pobreza o porque la guardan para el domingo y para sus viajes al pueblo. Llevan ellas adornos de plata, al rededor de la cabeza, en las orejas, al cuello, otras colgadas en el collar y especie de brazaletes; mas estos adornos se hacen más raros cada año, por la pobreza que aumenta» (ff. 46r-46v).

i. Aspectos de su personalidad y respuestas a las acusaciones de flojera, de inferioridad humana, de salvajismo, de robo (ff. 46v- $47 \mathrm{r}$, $47 \mathrm{v}, 48 \mathrm{r})$ :

[i.1.] «Es calumnia que los indios sean flojos en su gran totalidad, no lo son, aunque hay muy flojos entre ellos; si en alguna parte aún no cultivan el campo como sería de desear; es por falta de caminos para trasladar los productos al mercado, opor la pésima cualidad del suelo que ocupa o por no tener ya bueyes para el trabajo».

[i.2.] «Respecto a la mentalidad de los indios los declara cierto escrito inferior a la raza chilena. Pero este juicio no corresponde a la verdad. Los progresos que hacen en los colegios, aunque no son iguales a los hijos de familias inteligentes, no son nada inferiores a los de muchos hijos de campesino, y tienen que luchar los alumnos indígenas con la dificultad del idioma. Cierto es que los adultos muchas veces tienen 
muy mala memoria y poca inteligencia, pero esto se ha de atribuir a la falta de educación».

[i.3.] «Los indios no son salvajes, no merecen este nombre, de ninguna manera, ya no son lo que eran antes, han hecho rápidos progresos en la civilización. De ordinario son muy bien tratables, agradables en el trato. Ellos son más tímidos que arrogantes, bien hay entre ellos quienes lo son, pero solo se pone así cuando están ebrios».

[i.4.] «El indio no roba como forzado por un instinto, sino que por mala conciencia».

[i.5.] «La mayor desgracia es para los indios su inclinación a la borrachera»

j. La condición indispensable para el conocimiento del indio: «No conoce al indio quien no habla su idioma» (f. 47r).

k. La moralidad: «Tampoco respecto a su moralidad es inferior el indígena al cristiano pecador. $\mathrm{Ni}$ en sus conversaciones ni en su conducta son peores que los civilizados. Las mujeres se cubren decentemente y en mi trato con los indios nunca he visto acciones impúdicas. Otras naciones no civilizadas se desnudan en la pesca, los indios pescan mucho en el mar, hombres y mujeres, internándose en él, pero siempre cubiertos decentemente. Algunos hombres hay a quienes gustan conversaciones perversas, hombres y mujeres lascivos, pero muchos otros son muy delicados en este punto, solo en la ebriedad se vuelven brutos» (f 47r).

1. El matrimonio: «La poligamia no es general, hoy día la minoría de los indios son polígamos. El lazo matrimonial no es tan firme como debería ser; todavía subsiste la costumbre perversa de vender a las niñas, aunque ya no tan general; los hombres a veces abandonan sus mujeres e hijos y van a la Argentina donde fundan otra familia, y dejan sola su mujer largos años sin socorrerla en nada. Entonces a veces la mujer cansada ya del esperar se junta con otro hombre. Más perversos que las mujeres son los hombres que aprenden la maldad en el trato de los civilizados» (ff. 47r-47v).

m. Los afectos, los sentimientos, la interioridad: «El indio ama de ordinario a su mujer y a sus hijos con amor tierno y su corazón está unido a su hogar y a su suelo. Se suele decir de los indios que 
tengan inclinación a la tristeza, y en realidad no es raro el hombreicidio [sic] entre ellos causado por sentimientos, fácilmente se acobardan y pierden toda fuerza para arrastrar las desgracias que vienen sobre ellos, y se taiman cuando se les reprende o creen que no sean amados; mas a pesar de esto que parece ser un rasgo característico de la raza americana, hemos encontrado entre ellos también muy amables, muy alegres de genio y parece que solamente el exceso de las desgracias y persecuciones que han de sufrir y que vienen sufriendo ya hace siglos, ha puesto a su genio este timbre de sentimentalidad» (f 47v).

n. La organización política: «Los indios no sienten ya ninguna organización política, sus caciques han perdido casi enteramente su influjo y autoridad; todos se someten al gobierno chilenos y a las leyes de la república» (f 47v).

5. Acerca de las ideas religiosas de los «indios modernos»: en la Prefectura hay diferencia entre los indios del sur que desde largos años están bajo el influjo de la predicación del Evangelio, ya son cristianos y acuden a las Misiones, y los del norte que viven más retirados de las Misiones, al pie de la Cordillera, y no son cristianos: allí los ancianos sostienen las costumbres antiguas, creyendo «en las antiguas supersticiones, aunque ya muy modificadas con ideas cristianas. Todos reconocen el Dios de los cristianos como el supremo ser, saben del cielo y del infierno, con pocas excepciones sabrán también la redención por N. S. Jesucristo, y la creen también, sin embargo no hacen caso de estas verdades, obstinándose en que Aquel fue el Dios que ayuda a los cristianos mientras que a ellos les asiste otro dios, o sea las almas de sus finados. Tienen ellos sus sacrificios de animales con un ceremonial no poco complicado, que hemos descrito en nuestro libro titulado «Lecturas Araucanas» de que se ha enviado un ejemplar a V. Excia., si no nos equivocamos. Estos sacrificios se repiten casi cada año, y hasta los indios cristianos no se avergüenzan de asistirles, con el fin de conseguir buenas cosechas y alejamiento de las calamidades. Puede ser que antiguamente todo este culto se dirigía a los espíritus buenos o malos o las almas de sus finados que creían ser pillanes que producen a su idea los fenómenos ígneos de la naturaleza, no se han conservado las oraciones que hacían antiguamente, pero hoy día nombran mucho el Ngenechen (dominador de los hombres), juntan- 
do con este nombre la idea del Dios que lo domina todo y es Criador de todo al par que también invocan los espíritus de sus finados. Ceremonias semejantes que en las rogativas se repiten en las curaciones de los enfermos hechas por las machis o curanderas que atribuyen la causa de las enfermedades al influjo del Huecufu (espíritu malo) o de unas ánimas perjudiciales (nvitran alvue), ánimas peregrinas. También los entierros tienen todavía carácter religioso en sentido de las supersticiones antiguas. Sin embargo, los indios entregados aún a estas supersticiones no saben darse cuenta de lo que creen o hacen, sus ideas son ideas confusas, y prácticas inveteradas y tradicionales que tal vez subsistirán secretamente aun largos siglos después de haberse convertido ya toda la raza al cristianismo, así como también en Europa hoy día subsisten costumbres que se han conservado desde la era del paganismo» (ff. 48r-48v).

6. Datos estadísticos: la casa central, que es la residencia del Prefecto Apostólico, se encuentra en la ciudad de Valdivia, mientras las instalaciones misionales capuchinas (casa, iglesia y capilla de frailes, capilla y colegio de monjas) se encuentran en la provincia de Cautín (en el pueblo de «Bajo Imperial» hay la Iglesia Misional, otra en el Puerto Domínguez a orillas del lago de Budi, una Capilla de las Monjas en el Colegio Stella Maris, 2 capillas en reducciones de indios, Boroa, Llaima en Cunco, Lonquimay, Padre Las Casas, María en Gracias, frente a Lautaro), en la provincia de Valdivia (Toltén con una Capilla rural en Queuli, Purulon, Panguipulli, Coñaripe, Pelechuquin con capilla rural en Pidei, San José con capilla en Cuyingüe y Meliquina, Villarrica con una capilla en el Colegio de las Monjas, una en Pucón y otra en Manchue, Quinchilea) y en la provincia de Llanquihue (Quilacahuin, Trumag, San Juan de la Costa, San Pablo, Rahue). En todas estas Misiones trabajan fuera del Prefecto Apostólico 23 Misioneros sacerdotes y 21 hermanos legos Capuchinos de la provincia de Baviera, un sacerdote italiano y otro suizo de la misma Orden y 2 sacerdotes seglares. Además existen 2 padres Capuchinos bávaros que hacen función de cura y sotocura en la Parroquia de Río Bueno que antes del nuevo arreglo era Misión. Al trabajo de los Misioneros toman parte las Hermanas Maestras de la Sta. Cruz de Menzingen con un total de 84 Religiosas, de las cuales 47 están al cargo de seis internados. Su casa central con noviciado la tienen en Río Bueno que por la división territorial entre la Diócesis y la Prefectura ha quedado 
fuera del territorio de esta. El número total de los indígenas que existen en la Prefectura es 53.600; los indígenas católicos son 32.000, los indígenas infieles o metodistas son 21.600 (ff. 49r-49v).

7. Causas que se oponen a una más rápida evangelización:

a. El aislamiento de sus habitaciones: las misiones que existen todavía del tiempo que anterior a la pacificación estaban en medio de los indios pero con el tiempo «se han retirado estos o más bien fueron repelidos por fuerza o astucia, estableciéndose a mucha distancia de las Misiones» (f. 50r).

b. La inclemencia del clima y los malos caminos y muchos ríos caudalosos que hay que pasar.

c. "El sobrecargo de trabajos para los Misioneros. La existencia en nuestro territorio de los colonos nacionales y extranjeros cuyo número ya es superior al de los indígenas, obliga a los Misioneros a dedicarse a su pastoración [sic] con perjuicio de la evangelización de los indígenas. Días enteros están ausentes de la Misión, fatigándose en penosos viajes para llevar los auxilios a los moribundos. Además les incumbe y ocupa su tiempo la regencia de los internados, el catequismo en las escuelas fiscales y misionales; varios Padres han de hacer servicio de preceptores en los internados, otros están muy ocupados en las construcciones o han de dirijir los trabajos a los dichos internados. Los padres entendidos en medicina gastan mucho tiempo en atender a una numerosa y molesta clientela de enfermos que acuden a ellos en pedir curaciones y remedios, mas casi a todas las Misiones recurren los enfermos para este fin por la piadosa confianza que tienen en la virtud del Misionero o sea porque allí la visita de un doctor importa [sic] un desembolso de 100-200\$. En fin ayudan a los indios en la defensa de sus terrenos, y patrocinándolos contra sus atropelladores, escribiéndoles solicitudes y recomendaciones, dándoles consejos o prestándose a las autoridades» (ff. 50r-50v).

d. La falta de catequistas y la imposibilidad de formarlos: difícil formarlos sobre todo por «el disgusto a que está expuesto el catequista por la mala voluntad de unos indios malvados que tratan de desatraer los catecúmenos denigrando las intenciones del catequista» (f. 50v). 
e. La dificultad del idioma: aún mayor "porque los Misioneros no viven entre los indios y estos siempre se la presentan con intérprete. Además no está completamente conocido el idioma para dar expresión precisa y correcta a los términos teológicos» (50v).

f. Las ocupaciones de los indios: en los pocos meses de buen tiempo los indios están ocupados en el campo, y a los misioneros les resulta difícil reunirlos en sus casas para la instrucción religiosa. «Desde una serie de años no tiene otro anhelo que su radicación definitiva, mil veces pedida a las autoridades, pero que se viene realizando con mucha lentitud. Entretanto siguen luchando desesperadamente por la defensa de su suelo y sus bienes contra la avaricia descarada de particulares y de empresas colonizadoras, de cual lucha les resultan continuos pleitos, viajes para presentar sus reclamos y después nuevos disgustos por no haber amparo para ellos y salir casi siempre con la suya sus astutos adversarios» (ff. 50v-51r).

g. La falta de interés para las cosas inmateriales: «en la gran mayoría de los adultos enteramente rudos en ciencia y su pesadez para memorar los rezos y la doctrina. Parece que nos les es posible fijar su atención en lo que se les está enseñando; por eso ni la cosa más sencilla queda en su memoria. Así son muchos de los adultos, hombre como mujeres; no trabajan con la cabeza» (f. 51r).

h. La poligamia y la inconstancia de los recién casados: «Los jóvenes quieren probar primero a las niñas por algunos años para saber si se acostumbran con ellas, antes de concertar un casamiento eclesiástico. Otro vicio de los indios es la embriaguez. [...] Aquellos que viven cerca de los pueblos, hombre y mujeres, por aprovechar tanto la ocasión de embriagarse, se vuelven brutos, incapaces de aceptar una instrucción religiosa» (f. 51r).

i. El mal ejemplo de muchos cristianos chilenos y extranjeros: se constata el «descuido en el cumplimiento de sus deberes religiosos, o completo abandono de ellos, su inmoralidad y codicia. Muchos indios infieles ya nos han dicho: «Somos mejores que los cristianos». Mas hay que constatar que hay también familias cristianas muy buenas que no dejan de ejercer buen influjo sobre los indios haciendo que hagan bautizar a sus hijos, que se casen, y que llamen al Misionero para recibir auxilios» (f. 51v). 
j. La propaganda de las congregaciones metodistas: estos «tienen un gran colegio de niños y niñas en Quepe, estación ferrocarrilera, la segunda al sur de Temuco, y que disponen de mucho dinero para la propaganda de sus errores» (f. 51v).

8. Los medios que los capuchinos practican para evangelización a los indios son:

a. Las escuelas y principalmente los internados para hombres y mujeres, con enseñanza de oficios. «Es un medio soberano e indispensable para asegurar la educación religiosa tanto de indígenas como de los hijos de campesinos chilenos. Suprimir uno de nuestros internados bajo cualquier pretexto sería un desatino enorme. No es pequeña la suma total que da el Gobierno chileno para nuestros colegios, bien que no alcanza ni a lo lejos para cubrir los gastos» (ff. $51 \mathrm{v}-52 \mathrm{r})^{38}$.

b. Las capillas rurales: se dice haber ya «edificados un buen número y varias otras están en construcción» (f. 52r).

c. Las capillas entre los indios: «para acercarse más a los indios será necesario hacer capillas entre ellos en sus mismas reducciones, como tenemos una en Wapi y otra en Huiliu, y entonces se podrá enseñarles en su idioma». Se plantea un problema de método misional: en efecto, los misioneros en los meses de verano recorren su territorio de misiones pero, "como las casas o chozas de los españoles más se prestan, para celebrar los divinos misterios y los indios no tienen cómo mantener al Misionero aunque pague su sustento, tales Misiones mayormente han salido a favor de los españoles, y los indios vienen solamente a bautizar a sus hijos, o confirmarlos o a casarse; (ff. 52r-52v).

38 La relación reporta algunos interesantes datos sobre el tema, según las cifras del año 1910: A) el número total de niños es de 1.581 (en escuela y colegios son 821; las niñas son 760); el número total en los internados es de 1.104 (de ellos son indígenas hombres 477 y mujeres 205); B) los internados se hallan en las misiones siguientes: internados de hombres en Bajo Imperial, Boroa, Padre Las Casas, Villarrica, Panguipulli, Purulon, San José, Quilacahuin; de niñas en Bajo Imperial, Villarrica, Quilacahuin, S. Juan de la Costa. «Todos estos Colegios se han venido fundando desde el año 1901. Pensamos aumentas los internados de niños y hemos empezado a fundar en los pueblos escuelas al modo de las parroquiales, regentadas por las Hermanas Maestras de la Sta Cruz de Menzingen» (f. 52r). 
d. El estudio del idioma indígena: esto con la «publicación de un diccionario, español-araucano y viceversa, de pláticas, etc. en el mismo idioma. En los meses de invierno vienen cada dos meses Padres a Valdivia para iniciarse o perfeccionarse en su conocimiento" (f. 52v).

e. La defensa de los intereses materiales de los indígenas: los indios "como consta, son víctimas de incesantes atropellos y abusos de parte de los civilizados» (f. 52v).

f. La fundación de la Congregación Mariana en los internados: de tal manera se mantendría allí los educados, quedando en contacto con los misioneros.

g. Finalmente se comunica que «se ha hecho también mucho en el sentido de influir al Supremo Gobierno para que se prohíba la poligamia, la venta de las niñas, se ataje la embriaguez y se les ponga dificultades para no realizar sus rogativas, aunque hasta ahora casi nada se ha alcanzado» (f. 52v).

\section{Las informaciones de Monseñor Sibilia y las primeras instruc- CiOnes de la Santa Sede}

En el mencionado fascículo 38 se conserva la minuta ${ }^{39}$ del texto enviado por el internuncio Sibilia a la Santa Sede en fecha 11 de febrero de 1912, relación $\mathrm{N} .147^{40}$. La minuta recoge las informaciones contenidas en las

39 ASV, Arch. Nunz. Cile, fasc. 38, ff. 87-123.

40 La minuta lleva la misma fecha de la relación enviada a la Santa Sede (Santiago, 11 de febrero de 1912), el mismo numero de protocolo (N. 147) y el título «Evangelizzazione degli Indiani in Cile». Ni en ASV, ni en S.RR.SS. hemos podido encontrar el original de la relación -con el adjunto y los ocho mapas geográficosque monseñor Sibilia envía al cardenal Merry del Val el 11 de febrero de 1912, N. 147. El cardenal Merry del Val responde el 9 de abril de 1912, N. 56602 (original en ASV, Arch. Nunz. Cile, fasc. 38, f. 136r; minuta en ASV, Segr. Stato, año 1912, rubr. 17, fasc. único, f. 2r): por ende la relación de Sibilia ha llegado a la Secretaria de Estado. Sin embargo, la relación de Sibilia, el adjunto y los ocho mapas geográficos (mencionados también en la minuta), no se hallan en el Archivio della Nunziatura del Cile, donde se conserva solamente la minuta, ni se encuentran en AA.EE.SS. perteneciente a S.RR.SS. (fondo Sessioni, fondo Stati Ecclesiastici y fondo Cile); tampoco se encuentran en el Archivio della Segreteria di Stato donde efectivamente deberían estar, justamente en ASV, Segr. Stato, año 1913, rubrica 17 , donde se han puesto los documentos inherentes a esa temática 
relaciones de los misioneros, la noticias adquiridas directa o indirectamente por el internuncio y las sugerencias que la Santa Sede le ha pedido enviar. A continuación se da noticia de los elementos fundamentales.

Después de mencionar el encuentro con el enviado papal, P. Genocchi ${ }^{41}$, Sibilia escribe haberse ocupado del encargo recogiendo informaciones de las «mejores fuentes», viajando personalmente entre los araucanos y otorgando a un capellán castrense las facultades apostólicas necesarias para socorrer espiritualmente a los indígenas de la Isla de Pascua "privados de todo auxilio religioso» (f. 89) desde 12 años.

El texto es organizado geográficamente de norte a sur, desde la Araucanía hasta Magallanes, incluyendo también la Isla de Pascua.

Con referencia a la Araucanía asignada a los franciscanos el internuncio escribe haber recogido otras informaciones en las conversaciones tenidas durante el viaje en la Provincia Franciscana; en efecto, el internuncio visitó personalmente la misión viajando a Collipulli en marzo de $1911^{42}$. A propósito de la dificultad constituida por la dispersión

(exactamente 69 números de protocolo). Allí se hallan dos otros mapas: Croquis de la zona territorial del Río Putumayo ocupada por las empresas J.C. Arana y Hermanos comprendida entre los Ríos Yapuré, Putumayo, Cara-Paraná y Puerto Tecna: ASV, Segr. Stato, año 1913, rubr. 17, fasc. 4, f. 110/b; Colombia: ASV, Segr. Stato, año 1913, rubr. 17, fasc. 6, f. 19. Como se ha dicho, no poseemos el original enviado por Sibilia pero las instrucciones dadas en la respuesta de Merry del Val coinciden con algunos de los puntos y temas que el internuncio ha dejado escrito personalmente en la minuta que poseemos y garantizan -junto a las relaciones de los misionerosaquellas informaciones que de la minuta se extraen y utilizan en este estudio. Hay además que agregar que en el citado fascículo 38 se hallan también varias hojas manuscritas que han servido como apuntes para el trabajo de síntesis hecho en la Internunciatura; estas no llevan fecha y se encuentran en ASV, Arch. Nunz. Cile, fasc. 38, ff. 60-73.

41 Como los demás Representantes Pontificios en América Latina, también Sibilia, con despacho N. 51635 del 13 de julio de 1911, ha sido informado de la decisión del Papa de enviar a América Latina al P. Genocchi, ya Procurador General de los Misioneros del Sagrado Corazón, considerado «persona competente y experta en la obra de las Misiones» para llevar a cabo una visita sobre la condición de los indígenas en las diferentes Repúblicas: ASV, Arch. Nunz. Cile, fasc. 38, ff. 26r-27v.

42 «...llegó a Collipulli el señor internuncio apostólico monseñor Sibilia acompañado por su secretario, algunos superiores de la Orden de San Francisco [...] el señor Sibilia iba a imponer el sacramento de la confirmación a los niños que se educan en las escuelas que sostiene la Orden de San Francisco»: «Monseñor Sibilia en Collipulli», en El Misionero Franciscano [Revista Mensual Ilustrada Franciscana], 
geográfica de los indígenas pertenecientes a «la valiente e indómita raza Araucana ${ }^{43}$, Sibilia anota que el "vasto territorio que en el pasado pertenecía a sus antepasados [...] ahora, dividido en grande posesiones o haciendas, es posesión de muchos propietarios chilenos» y que, debido a su postura contraria a la religión, estos últimos dificultan la labor de los misioneros (f. 91).

Con referencia a la Araucanía asignada a los capuchinos el representante Pontificio ve en el problema de la jurisdicción eclesiástica con el Obispado de San Carlos de Ancud la raíz de la debilidad de la acción pastoral. Sucesivamente subraya la obra social llevada a cabo por los misioneros capuchinos, ya sea por su pericia medica («Algunos Padres, que se entienden de medicina, gastan mucho tiempo en atender a la numerosa y molesta clientela de enfermos que recurren a los Misioneros con piadosa confianza»: f. 101), ya sea por su defensa de los derechos de los nativos ("Finalmente los Misioneros intercediendo frente las autoridades civiles, ayudan a los pobres indios también en la defensa de sus terrenos que ávidos especuladores con la violencia o con el engaño buscan raptar de sus manos»: ff. 101-102). A propósito del deseo de los araucanos de ser considerados como ciudadanos chilenos, y por ello tener escuelas y colegios y hospitales, el internuncio no descuida comunicar que los indios han pedido su ayuda y que él se ha dirigido personalmente a las autoridades civiles, sin obtener nada: los araucanos «se han dirigido a las autoridades civiles también por medio del internuncio que ya ha hablado varias veces con el Presidente de la República, con el Ministro de Colonización y con otros personajes influyentes en la política. Pero no se han obtenido más que bellas promesas» (f. 103). También en el territorio de la misión capuchina, como en la provincia franciscana, se constata una presencia protestante, concretamente de los Metodistas ${ }^{44}$, con su colegio y su propaganda religiosa (f. 104).

Chillán, XVII (n. 204, 1911), 394-395. El artículo de la revista franciscana es sacado del diario La Unión de Santiago del 30 de marzo de 1911.

43 Así se encuentra anotado en esas hojas de apuntes antes citadas: ASV, Arch. Nunz. Cile, fasc. 38, f. $61 \mathrm{r}$.

44 Con referencia al tema de la presencia Protestante y Metodista: Florrie SNow, Historiografía Iglesia Metodista de Chile. 1878-1918, I-II, Concepción, Ediciones Metodistas, 1999; La Religión en Chile del Bicentenario. Católicos, Protestantes, Evangélicos, Pentecostales y Carismáticos, Miguel A. Mancilla - Luis Orellana (Editores), Concepción, Ediciones RELEP, 2011. 
Finalmente Sibilia da comunicación de la importancia de las escuelas y de los colegios para niños y niñas, siendo la educación «uno de los medios más eficaces y más seguros para la evangelización de los infieles» (f. 109).

Sucesivamente la relación considera a los pueblos nativos del Archipiélago de Chiloé, de Magallanes y de la Isla de Pascua.

Refiriéndose a los chonos del Archipiélago de Chiloé, el internuncio tiene palabras de piedad por estar ellos «completamente abandonados y hallarse sumergidos en las tinieblas de la infidelidad y del error» (f. 110) y son «sumamente pobres» (f. 111). Los chonos son "pacíficos, tímidos, y huyen del trato y del consorcio de los extraños que ordinariamente los explotan» (f. 111). Además de recordar que los antepasados de los chonos han sido evangelizados por los jesuitas (dejando abierto el tema de la efectiva coincidencia con los antiguos chonos ${ }^{45}$ ), escribe lo que también P. Correa ha propuesto (aunque su texto es posterior, como se puede ver por la fecha $)^{46}$ y hace referencia a la parroquia de Melinka, la última de la diócesis de Ancud, como punto de partida para los misioneros, ya que los habitantes de Melinka tienen relación con los indígenas identificados con los chonos.

Con respecto a Magallanes, el internuncio hace referencia a propaganda protestante (f. 113), y dice también que los indígenas yaganes y alacalufes podrían ser llamados «los nómadas del mar» (f. 114).

Finalmente recorre las etapas eclesiásticas de la «Isla de Pascua (llamada Rapa-Nui)» (f. 117) refiriéndose a la visita del capellán Valenzuela en marzo de 1911 y menciona la posibilidad de «confiar establemente al Vicario Castrense el bien espiritual» (f. 120) de sus habitantes.

En relación a la ayuda que puede esperarse del Gobierno chileno en vista de una «obra de tal alto interés religioso y civil» (f. 121), el internuncio afirma que «no puede dudar de que el Gobierno se manifestará con buena voluntad y a lo mejor será también generoso en promesas,

45 «Entre el Golfo de Penas y las islas meridionales del archipiélago de Chiloé vivieron hasta fines del siglo XVIII los indios chonos. La mayoría de ellos eran nómades»: Joseph Emperaire, Los nómadas del mar, Santiago, Universidad de Chile, 1963, 56.

46 Se puede suponer que el Internuncio haya recibido informaciones también en los diálogos con personas «expertas», por ejemplo el «optimo Mons. Jara», Obispo de Ancud, como se lee en la minuta de Sibilia: ASV, Arch. Nunz. Cile, fasc. 38, f. 111. 
pero que después sigan los hechos, a uno no le cabe más que esperarlo» (f. 121).

Finalmente en la minuta se sintetizan también las dificultades y los remedios que en ese entonces se encontraban en vista de la evangelización y promoción humana de los indios, tales como ya se han podido conocer por medio del informe capuchino.

En respuesta a la relación de Sibilia, el 9 de abril de 1912 en el despacho N. 56602, el cardenal Merry del Val comunica al internuncio las primeras indicaciones humanitarias y pastorales de la Santa Sede y las próximas futuras intenciones de esta ${ }^{47}$. El despacho manifiesta por ende el pensamiento de la Santa Sede, junto a la iniciativa que está madurando en favor de los pueblos nativos del continente latinoamericano, o sea la encíclica. A continuación se reproduce la primera parte del texto, que justamente puede considerarse como expositiva del pensamiento de la Santa Sede y de su solicitud pastoral.

[f. 136r] [Membrete] Segreteria di Stato di Sua Santità

N. 56602

Dal Vaticano, 9 Aprile 1912

Ill.mo e Rev.mo Monsignore

Lampio rapporto, il relativo Allegato e le otto Carte Geografiche, che la S.V. R.ma. mi trasmetteva in data dell'11 Febbraio n.s., N. 147, intorno alla condizione religiosa, morale e materiale degli Indiani in cotesto territorio Cileno, pone in evidente rilievo la necessità di tentare ogni mezzo possibile per migliorare in qualche modo le sorti di quei poveri infelici. Già da tempo la Santa Sede è preoccupata a loro riguardo; e la nota missione affidata nello scorso luglio al P. Genocchi fu appunto ispirata dal fermo proposito di accorrere con opportuni ed efficaci provvedi [f. 136v] menti in soccorso di quei poveri Indiani, vittime delle barbarie e delle speculazione non solamente dei loro connazionali, ma degli stessi europei civilizzati.

Grazie a Dio, non mancano fondate speranze di potere fra breve fare qualche cosa di concreto a pro di quei derelitti. Intanto o debbo ringraziare la S.V. per le molte e dettagliate notizie comunicatemi col suddetto suo rapporto, le quali sono un novello prezioso elemento per viemmeglio, come suol dirsi, orientarsi nel conseguimento del suo scopo.

ASV, Arch. Nunz. Cile, fasc. 38, ff. 136r-138v. 
Ma nel frattempo, ossia mentre la S. Sede sta considerando la generale situazione in proposito, la S.V. farebbe cosa assai benemerita se, valendosi opportunamente delle informazioni raccolte, e della sua autorità ed influenza, iniziasse qualche [f. 137r] salutare provvedimento, dove e come le circostanze lo permettessero, a vantaggio dei poveri indiani.

[...]

R. Card. Merry del Val

[en la parte abajo] Mgr. Enrico Sibilia, Internunzio Apostolico, Santiago

El despacho contiene también algunas concretas sugerencias para la asistencia a los diferentes pueblos. Mientras se invita el internuncio a tomar contacto con el obispo de San Carlos de Ancud para solicitar su celo apostólico hacia los araucanos, hacia los chonos monseñor Sibilia debe intervenir, sin demora alguna, para que algún religioso se interese en ellos. Naturalmente la intervención estatal constituye una valiosa ayuda, valorada por la Santa Sede, sobre todo con respecto a los medios de transporte para los viajes y las trasferencias de los misioneros. Igual preocupación se expresa hacia los indios de Magallanes y en favor de los habitantes de Rapa Nui; para estos últimos se requiere que se solicite la intervención del Vicariato Castrense. Finalmente, el secretario de Estado menciona los remedios sugeridos por el internuncio y pide mayores detalles, «utilísimos y también indispensables al conocimiento de la Santa Sede» (ff. 138r-138v).

\section{Conclusiones}

Con la encíclica Lacrimabili statu Indorum dirigida a los pastores, a las Iglesias, a las misiones y a los pueblos de América Latina, el Papa Pío X reclama la atención sobre la dramática y escandalosa situación de esclavitud e injusticias sufridas por los pueblos originarios en algunas regiones del continente a inicios del siglo XX, las condena, sale en defensa de los indígenas y promueve su evangelización. Es un documento magisterial que destaca la solicitud pastoral de la Santa Sede para los pueblos latinoamericanos.

Pío X está interesado a la realidad latinoamericana, cuya originalidad y problemáticas se habían dado a conocer en Roma con mayor precisión durante el Concilio Plenario Latinoamericano de 1899, convocado por su predecesor León XIII. El pontificado de Pío X es centralizador y reformador, y al mismo tiempo pastoral, preocupado -en el caso lati- 
noamericano- por la supervivencia, la libertad y el bienestar de aquellos indígenas que aún no son cristianos, sin descuidar su educación en la fe. Es un pontífice que se deja interpelar por los dramas y las problemáticas de los pueblos originarios de Latinoamérica y que, después de recibir las informaciones de los Representantes Pontificios y de su enviado en América Latina, interviene en la escena internacional en razón de su rol pastoral universal, queriendo "trabajar en favor de los indios" para así socorrer las numerosas y diferentes etnias del continente.

Junto a la condición indígena presentada anteriormente por medio del informe de los capuchinos, algunas dimensiones fundamentales y elementos trasversales merecen un relieve particular.

1. Un primer elemento fundamental que emerge de los documentos debe atribuirse al conocimiento adquirido por los misioneros en el contacto cotidiano con los indígenas. Los misioneros hablan con certeza porque conocen acertadamente. Su conocimiento no es abstracto, ni frío; más bien es realista y apasionado por la persona del indígena e, incluso, por la naturaleza chilena. Los misioneros tienen un "conocimiento afectivo» de los indígenas, de su idioma, de su cultura, de su tierra hasta expresar una preocupación «ecológica» por los inmensos territorios araucanos y patagónicos cubiertos de ricos bosques cuya madera atrae los intereses económicos de los comerciantes chilenos y extranjeros. En el aparato crítico se ha querido indicar las referencias biográficas de los misioneros autores, y/o redactores, de los informes. Se trata de personas que han recibido una sólida formación espiritual e intelectual: estudian los idiomas y componen diccionarios y varias obras de carácter lingüístico y etnográfico; conocen la religiosidad, las costumbres, la mentalidad de los pueblos originarios desde Arauco a Magallanes; conocen y viven personalmente las tensiones presentes en el país y se hacen cargo de las necesidades de los indígenas, a menudo compartiendo su pobreza, muriendo atravesando los ríos caudalosos, volviéndose sus amigos, llevando dentro de sí los dramas de la época y también las dificultades que surgen por ser identificados con el mundo de la «modernización».

2. El fin de la labor de los misioneros es el anuncio de Cristo y su Evangelio a los indígenas que aún lo desconocen. En los documentos considerados se observa la relación entre evangelización y educación, y también entre evangelización y civilización; sin embargo, hay que 
subrayar que se refieren a la "civilización cristiana» y no a la "modernización» del Estado. Para educar los misioneros utilizan sus pocas estaciones misionales, las capillas y las casas de familias, y sobre todo levantan colegios. La educación es dada preferentemente a los niños y también a las niñas indígenas; al cuidado de las niñas se dedican las hermanas (franciscanas y salesianas). A pesar de las diferencias de pueblos y regiones, de la escasez numérica de los misioneros, de su pobreza de vida y de medios, las fuentes señalan otros elementos externos que obstaculizan el camino de educación a la fe: el indiferentismo religioso de los indígenas, la persecución de los indígenas no cristianos hacia los de su pueblo que se bautizan, la propaganda protestante, los mismos civilizados (cristianos, chilenos, extranjeros) con su avidez y violencia. La afirmación de las dificultades relativas a la inteligencia de los indígenas no es aceptada por los misioneros como un defecto inherente a su naturaleza humana, sino como el resultado de la ausencia de educación. Las dimensiones educativa y evangelizadora se reclaman y se ponen al servicio del «otro».

3. La afirmación de la dignidad humana del indígena en cuanto persona -patrimonio cultural de origen bíblico y cristiano-, y por ende la promoción humana integral del individuo y de los pueblos nativos, en la justicia y en los derechos, constituyen otros importantes elementos de la obra de los religiosos y religiosas, obra «apostólica y humanitaria». Estos denuncian las injusticias que los pueblos indígenas sufren por la codicia y las violencias de los «civilizados», la situación de pobreza en la que viven, causada por la sustracción de sus tierras por los Gobiernos, por los particulares o por las sociedades colonizadoras, también extranjeras y occidentales. Piden el respeto de los derechos de los indígenas, para que también sea posible paulatinamente su integración en el país que "avanza» hacia el sur. Frente a la construcción del Estado-Nación y su proyecto modernizador y uniformador, los misioneros sostienen más bien la opción de la integración en la justicia y en la caridad, cuya dimensión fundamental es la educación e instrucción. Sin duda los misioneros tratan también de influir en las costumbres que juzgan contrarias a la dignidad de la persona a la luz de la razón y del Evangelio (como por ejemplo robar, emborracharse y matar, concebir de forma inestable y poligámica la relación afectiva, vender a las hijas, vivir un indiferentismo religioso); de su labor pastoral tampoco están exentas ideas y costumbres de sus 
países de origen, que continuamente ellos deben someter a la realidad misional, adecuándolos a ella.

4. Otro elemento es representado por la dimensión pastoral presente en los diferentes sujetos eclesiales. Expresada en primer lugar por la entrega y la actividad de los misioneros y de los indígenas cristianos sus colaboradores en los territorios de misión, la dimensión pastoral se encuentra también en las instrucciones de la Santa Sede y en la acción de los Representantes Pontificios. En el caso chileno, el papel desarrollado por el Representante Pontificio muestra la íntima unidad entre la acción diplomática y la pastoral que, aunque sea un elemento constitutivo del rol del Representante Pontificio, merecería ser profundizado en consideración de la particular proyección latinoamericana de la encíclica de Pío X. La misma solicitud pastoral del primer pontífice elegido en el siglo XX -solicitud que alcanza al "otro» en los pueblos nativos de América Latina concretándose en la encíclica Lacrimabili statu Indorum- merecería ser considerada no solamente como organizadora sino también como inspiradora y alentadora de la labor misional de las órdenes, las congregaciones, las diócesis y el laicado católico presentes en Chile, como en otros países del continente latinoamericano; sería entonces una solicitud pastoral, la de Pío X, que a inicio del siglo XX inauguraba la invitación a todas las personas de buena voluntad, incluyendo a los responsables de las instituciones civiles y eclesiásticas, a unir sus esfuerzos «en pro de la Religión y de la dignidad humana». 
Resumen: La solicitud pastoral del Papa Pío X (1903-1914) hace que la Santa Sede se interese por los indígenas aún no bautizados del continente latinoamericano. Recibidas noticias desde la Amazonía acerca de las injusticias, atrocidades y explotación sufridas por enteros pueblos indígenas a comienzos del siglo XX, el pontífice pone en marcha la diplomacia pontificia y envía un delegado suyo para recoger informaciones que permitan un estudio de la situación en vista de una intervención papal en defensa de los indígenas que se concreta con la Encíclica Lacrimabili statu indorum de 1912. En el artículo se da cuenta de las fuentes inéditas de origen chileno de la encíclica, de la correspondencia entre la Santa Sede y el internuncio Pontificio en Chile y se presenta la fuente más extensa y rica de informaciones acerca de los indígenas y de su vida, de la labor misionera y de las dificultades que se encuentran en los territorios de la entonces Prefectura Apostólica de la Araucanía.

Palabras clave: Pío X, Encíclica Lacrimabili statu indorum, Evangelización y defensa de los indígenas en Chile, Santa Sede e Internunciatura Apostólica en Chile.

Abstract: The pastoral preoccupation of Pope Pious X (1903-1914) caused the Holy See to interest herself about the un baptized aborigines of the Latin American continent. Having received news from Amazonia informing on the injustice, the atrocities and the exploitation that entire indigenous populations were suffering there at the beginnings of $\mathrm{XX}$ century, the pontiff put the pontifical diplomacy in motion and sent a special delegate to gather information that would allow the study of the situation preparing the papal intervention in defense of the aborigines, that consisted in the Encyclical Letter Lacrimabili statu indorum of 1912. In the article, it is given account of the encyclical's inedited sources of Chilean origin, the correspondence between the Holy See and the Internuncio in Chile, and the richest and largest source of information about the indigenous populations and their life, the missionaries' labor and the difficulties found in the territories of the thencecalled Apostolic Prefecture of the Araucania, is presented.

Keywords: Pious X, Lacrimabili statu indorum Encyclical, Evangelization and defense of Chilean aborigines, Holy See and Internuciature in Chile. 
